INTERNATIONAL CONFERENCE ON ADVANCES IN AUTOMOTIVE TECHNOLOGIES 2016 - AAT2016 11-14 October 2016, Yildiz Technical University, Istanbul, Turkey

\title{
ADHESIVE CONTACT BETWEEN SILICON-BASED MEMS TOOTH SURFACES MODELLED BY THE MULTISCALE MULTI-BLOCK MODEL
}

\author{
${ }^{*}$ Nabeel Almuramady \\ School of Engineering, Cardiff University, \\ Cardiff, Wales, UK \\ College of Engineering, Al-Qadisiyah University, \\ Al-Qadisiyah, Iraq
}

\author{
Feodor M. Borodich \\ School of Engineering, Cardiff University, \\ Cardiff, Wales, UK
}

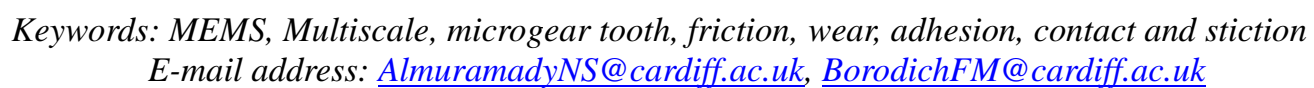

\begin{abstract}
The contact interactions between microgear silicon-based MEMS teeth working in a clean and a vacuum environment are under consideration. A new approach has used to determine the friction force and the coefficient of friction over the whole meshing surfaces of the teeth. In this approach, the dry friction force is calculated through the energy dissipated during sliding contact between two meshed micro-tooth elastic rough surfaces. The energy dissipated may be caused by the different physical and chemical interactions between the counterparts surfaces. Due to the vacuum environment, these mechanisms reduced to the energy lost due to the dissociation of chemical and van der Waals bonds, and the energy lost through the elastic interlocking between the asperities located on the meshing micro-tooth surfaces. There is no plastic deformation of the microgear tooth surface asperities due to their size and the Polonsky-Keer effect. A multiscale hierarchical elastic structure (a multiscale block) is used to model the surface asperities. The tooth block roughness has modelled at two scales specified by the character of interactions: atomic level, where chemical interactions occur, and adhesive subscale, where van der Waals interactions are significant. The adhesion layer is defined similarly to Maugis approximation. The adhesion force of each nanoasperity has assumed to be equal to the pull-off force in the BoussinesqKendall model and corrected by the Borodich no-slip coefficient. Atomic Force Microscopy (AFM) techniques have been used to measure the tooth roughness. It is argued that there be a high probability for stiction between the clean silicon surfaces due to very high values of the friction force between the microconjunctions. On the other hand, the tooth surfaces having functionalized carbon-based layers are much less prone to stiction. However, due to wear of the functionalized coating the probability of stiction will start to increase. The results of the simulation for both the non-functionalized and functionalized micro-tooth surfaces (silicon-based MEMS surfaces) are presented.
\end{abstract}

\section{INTRODUCTION}

Micro-Electro-Mechanical Systems (MEMS) are used in the wide variety of industrial and space applications [1-4]. MEMS are consist of a significant number of micro/nano components and the majority of them work in contact with each other to transfer the load and torque between MEMS parts. Advanced and highly sophisticated technologies are employed to miniaturise the mechanical and electronic MEMS elements. On the other hand, there are various challenges that may lead to device failure, in particular these related to the stiction [5], adhesion and friction [6]. Stiction is the key issue in the MEMS devices technologies and it is mostly defined as the unintentional adhesion (the static friction) that highly restricts the movements of the micro/nano elements. In this paper stiction is defined as the unintentional adhesion between the teeth that does not allow MEMS to work at all. Stiction may lead to structure failure or significantly reduces the MEMS reliability [7, 8]. Cold welding (cohesion) between micromachined device surfaces could occur when these surfaces are clean and work in the vacuum environment [5, 9-12]. Surface functionalization is one of the successful solutions to reduce cohesion and, therefore, to eliminate stiction [1].

Microgear is one the most important torque transmitter in MEMS. When it work there is contact between the teeth. If these teeth are clean and work in a vacuum then there is a high probability of sticking with each other and as a result for this cold welding occurred in the contact zone, which lead finally to structure collapse.

The MEMS surfaces may contact unintentionally during acceleration or due to presence of the electrostatic forces or the contact may be intentional when surfaces are shearing each other as in the case of microgear teeth contact. Stiction occurred in the contact region because the maximum force produced by the MEMS is less than the force of surface tangential interactions, 


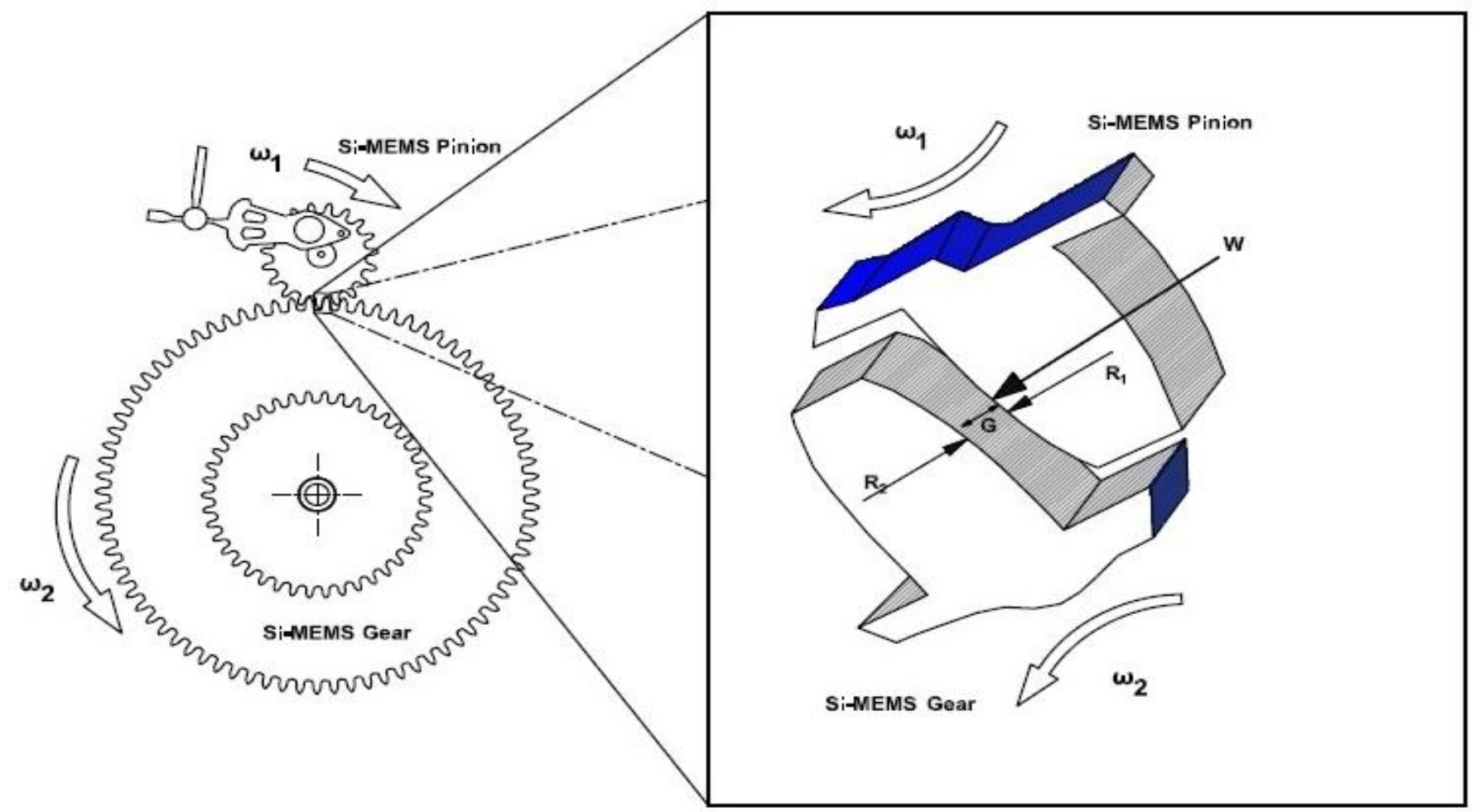

Fig. 1. A sketch illustrated the microgears meshing in MEMS devices.

and this sometimes leads to permanent adhesion between the surfaces (the cold welding).

Historically, silicon was the base of the integrated circuit (IC) technologies, so it is natural that it is the common material for MEMS, especially when to know that most of these techniques were borrowed originally from (IC) technologies [13]. Hence, the problems related to contact and stiction between teeth of the silicon-based microgear MEMS are under investigation.

The dimension of the meshing microgear as was taken as in [14]. Figure 1 shows a micro-pinion that is meshing with microgear. The gap between surfaces of microgears meshing teeth, which is different at each time step, is calculated using Hertz line contact theory.

In this study, a modified multiscale hierarchical model of an asperity is employed in order to simulate the work of multiasperity rough surfaces of MEMS microgear teeth as shown in Figure 2. $W_{\text {adhesive }}$ is denoted the width of the adhesive subscale where the van der Waals interactions are likely occurred.

The first version of model was introduced by Savencu and Borodich [15] for modelling a single multiscale asperity. The term 'scale' as defined as the term that reflects the capabilities of the asperity to model different physical-chemical mechanisms of interactions between surfaces. In the present model, the nanoscale of an asperity is mainly responsible for molecular and chemical interactions and the micro-scale is responsible for mechanical interlocking of asperities. Therefore, then the model is multi-scale, because the system is capable of modelling more than one mechanism of interaction.

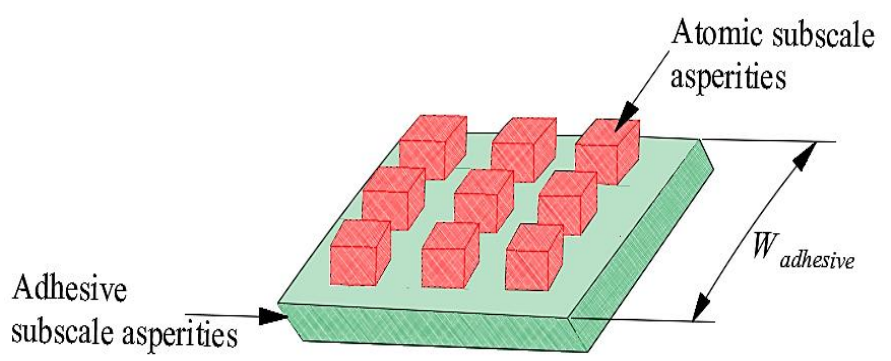

Fig. 2 sketches for multiscale hierarchical structure

The original model had to be modified to reflect particular features of MEMS structures. The modified model is multiscale, but it is not multilevel, as the asperities of the same generation are on the same height. Further, due to the nanoscale dimensions of the asperities of the microgear tooth, it does not have the micro-scale roughness.

In addition, the asperities do not have plastic deformations due to the Polonsky and Keer effect $[16,17]$. The effect can be formulated as the following statement: plastic deformation at an 
asperity micro-contact becomes difficult and then impossible when the asperity size decreases below a certain threshold size.

Thus, the present model has two nanoscales: atomic scale as the first subscale of nanoasperity and adhesive nanoscale as another subscale. The latter subscale reflects the dimensions where the van der Waals interactions are significant.

\section{FRICTION FORCE}

A new approach has used to determine the friction force and the coefficient of friction over the whole meshing surfaces of the teeth. In this approach, the dry friction force $\left(F_{f}\right)$ is calculated through the energy dissipated ( $U_{\text {diss }}$ ) during relative sliding distance $(x)$ between two meshed micro-tooth elastic rough surfaces

$$
F_{f}=U_{\text {diss }} / x
$$

This energy lost is due to dissociation of chemical and van der Waals bonds, and the energy lost through elastic deformation of nanoasperity during the contact cycle.

For a pure silicon surface, the dissociation energy due to break the chemical bonds between two silicon atoms $[18,19]$ is equal to $327 \mathrm{~kJ} / \mathrm{mol}$, hence the energy of one chemical bond is $5.4 e-19$ $J$. Then the total energy ( $U_{\text {Totalchem }}$ ) dissipated by chemical bonds at the moment $(t)$ is

$$
U_{\text {Totalchem }}(t)=n_{\text {atoms }}(t) U_{\text {chem }}
$$

where $U_{\text {chem }}$ is the energy of the dissociation of one chemical bond and $n_{\text {atoms }}$ is the current number of the chemical bonds between counterpart's surfaces. Using (3), one can find the total energy $\left(U_{\text {TotalvdW }}\right)$ dissipated by van der Waals bonds

$$
U_{\text {TotalvdW }}=n_{v d W} U_{v d W}
$$

where $U_{v d W}$ is the energy of the dissociation of a van der Waals bond, $n_{v d W}$ is the current number of the vdW bonds within the adhesive scale of contact. This energy is different at each time moment along the contact cycle due to variability of the number of nanoasperity in touch at that point. The energy spent for elastic deformation ( $U_{\text {elastic }}$ ) of a nanoasperity or the elastic interlocking between the counterpart's surfaces of the silicon microgears teeth is also taken into the account. Hence, the total energy loss is

$$
U_{\text {diss }}=U_{\text {Totalchem }}+U_{\text {TotalvdW }}+U_{\text {elastic }}
$$

Then it follows from (1) and (4) that the friction force can be calculated as

$$
F_{f}=\left(U_{\text {Totalchemical }}+U_{\text {TotalvdW }}+U_{\text {elastic }}\right) / x
$$

The numerical simulations show that $U_{\text {Totalchem }}(t)$ gives the greatest percentage in (4), and in turn in friction while $U_{\text {TotalvdW }}$ calculated by (3) gives roughly less than $40 \%$ of the total energy loss.

COF (the coefficient of friction) $\mu$ can be calculated as

$$
\mu=F_{f} /\left(F_{N}+F_{a d h}\right)
$$

Hence, it follows from the above expression and (5) that COF is

$$
\mu=U_{\text {diss }} /\left(F_{N}+F_{a d h}\right) x
$$

Here $F_{N}$ is the nominal normal force applied to the tooth surface in the contact zone, and $F_{a d h}$ is the force of adhesion between contacting surfaces. Hence, the equation (7) can be rewritten as

$$
\begin{aligned}
& \mu=U_{\text {chemical }} /\left(F_{N}+F_{a d h}\right) x+U_{v d W} /\left(F_{N}+F_{a d h}\right) x+ \\
& U_{\text {elastic }} /\left(F_{N}+F_{a d h}\right) x
\end{aligned}
$$

That is mean also the coefficient of friction will be:

$$
\mu=\mu_{\text {chemical }}+\mu_{v d W}+\mu_{\text {elastic }}
$$

Thus, as it has been mentioned, due to the vacuum environment, the mechanisms caused the energy lost reduced to the energy lost due to the dissociation of chemical and van der Waals bonds, and the energy lost through the elastic interlocking between the asperities located on the meshing micro-tooth surfaces (4).

\section{ADHESION FORCE}

The force of adhesion for one nano-asperity is assumed as the pull-off force according to Boussinesq-Kendall model, corrected with non-slip coefficient $\left(C_{N S}\right)$ introduced by Borodich $[20,21]$.

Let $F_{a d h l}$ be the adhesion force of one asperity and $n$ be the number of asperities in contact. Then one has

$$
F_{a d h 1}=\sqrt{8 \pi w_{12} E^{*} C_{N S} a^{3}} .
$$

Here $w_{12}$ is the surface energy calculated as

$$
w_{12}=A_{12} / 12 \pi D_{0}^{2}=1.31 \mathrm{~J} / \mathrm{m}^{2}
$$

For silicon, the Hamaker constant $A_{12}=1.1 \times 10^{-18} \mathrm{~J}$ [9] and the separation distance $D_{0}=1.49 \AA$ respectively. The half width $a$ of the silicon adhesive asperity is (see Figure 2)

$$
a=W_{\text {adhesive }} / 2=97.5 \mathrm{~nm} \text {. }
$$

Using (10), the total adhesion force $F_{a d h}$ at each point over the sliding distance can be calculated as

$$
F_{a d h}=n F_{a d h 1}
$$


The contact modulus for silicon gears can be calculated by substitution the corresponding values of Young's $E=161 \mathrm{GPa}$, and the Poisson's ratio $v=0.23[14,22]$, hence, it is

$$
E^{*}=E / 2\left(1-v^{2}\right)=85.15 G P a
$$

The no-slip coefficient can be found as [20,21]

$$
C_{N S}=(1-v) \ln (3-4 v) /(1-2 v)=1.044
$$

Adhesion layer thickness was assumed according to Maugis approach in Savencu and Borodich interpretation [15]. Therefore, the asperities of both the atomic and adhesive subnanoscales will jump into contact when they are within this layer of adhesion, as indicated in Figure 3.

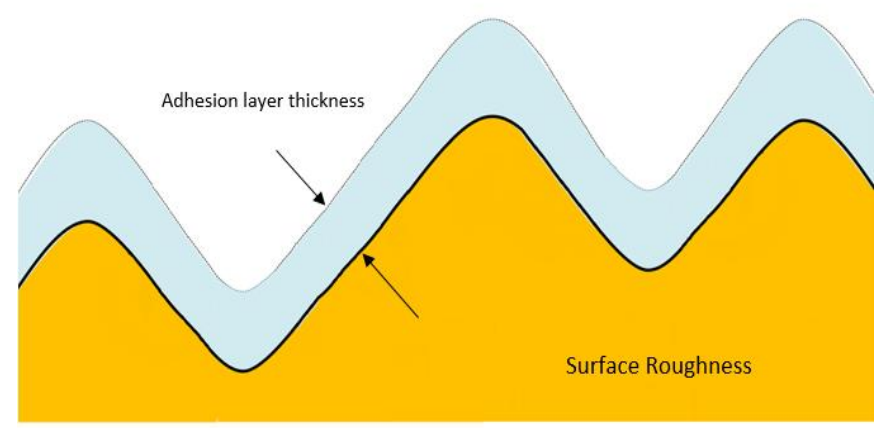

Fig. 3. Adhesion layer thickness.

\section{RESULTS AND DISCUSSION}

The external moment $\left(M_{e x t}\right)$ applied to the gear may be calculated as $M_{\text {ext }}=r_{2} F_{t}$ alternatively, it could be written as

$$
F_{t}=M_{e x t} / r_{2}
$$

where $F_{t}$ and $F_{f}$ are the tangential force and friction force respectively (Figure 4), and $r_{2}$ is the radius of the microgear (Figure 1).

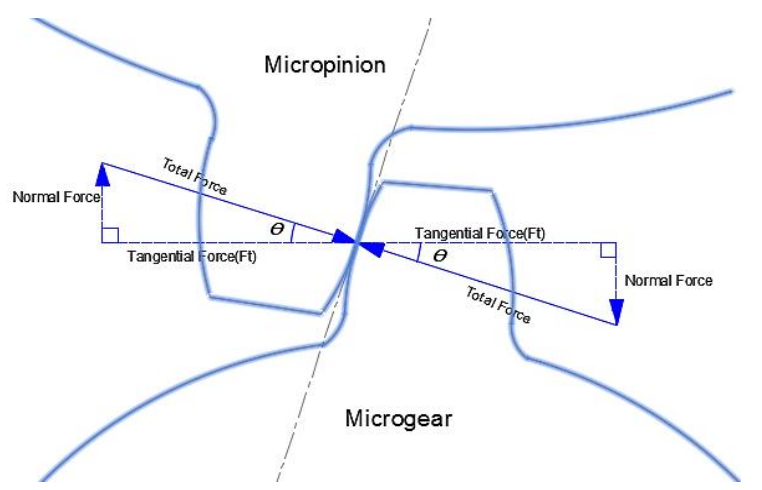

Fig. 4. The external moment on the meshing microgear MEMS teeth.
Therefore, if $F_{f}>F_{t}$ then there is a high probability for stiction and the microgear cannot work. If $F_{f}<F_{t}$ then there is some motion between microgear teeth and the stiction is overtaken.

Our simulations show that the probability of stiction between the silicon microgear MEMS teeth working in a high vacuum environment will increase rapidly because the surface contamination is progressively removed, in other words, there is no contamination between surfaces of the microgear MEMS teeth. If it is assumed that there is no stiction then the calculated values of $\mathrm{COF}$ are very high.

Figure 5 shows the amount of the total dissipated energy over the contact sliding distance between the MEMS teeth surfaces.

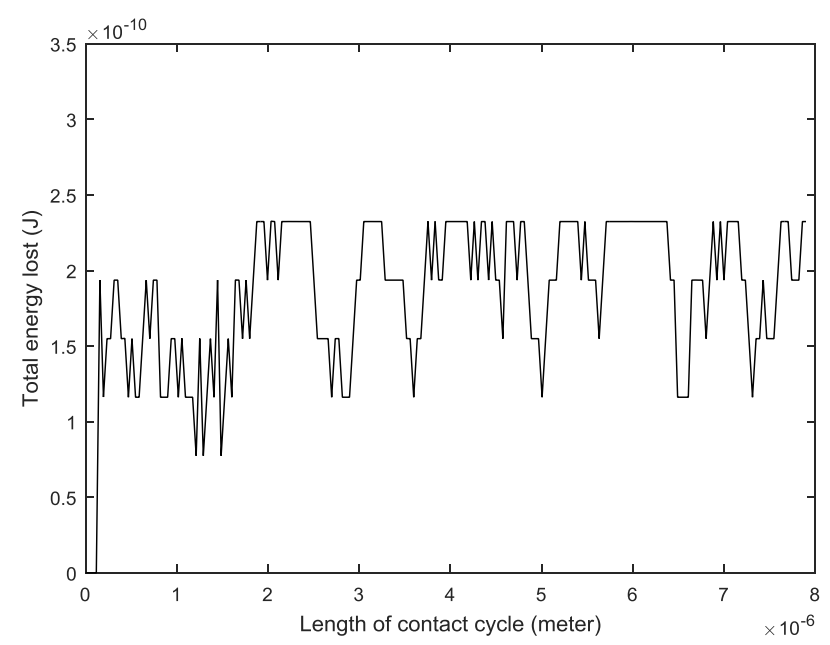

Fig. 5. Total energy dissipated during contact cycle.

One of the important mechanisms of the dissipated energy is the energy lost via the elastic interlocking between the atomic and adhesive subscale asperities, i.e. the energy lost when the asperities of the contacting counterparts microgear MEMS tooth surfaces are elastically deformed. Figure 5 shows the amount of the energy lost during the interfacing between these asperities.

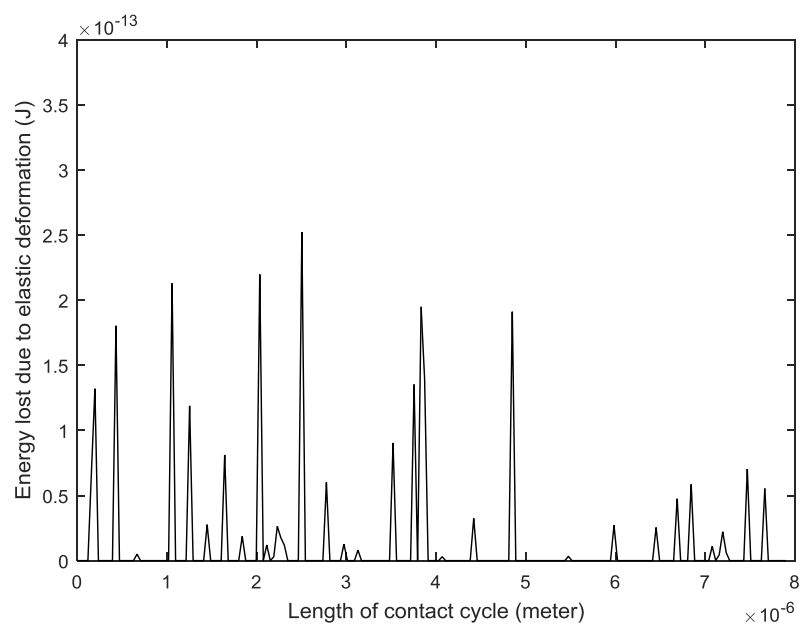

Fig. 6. Elastic Interlocking between the counterpart's surfaces of the silicon microgears teeth. 
It has been found that the friction force is higher than the tangential force, which is calculated to be equal to $2.82 \mathrm{E}-03 \mathrm{~N}$; therefore, there is a great chance for stiction between teeth in the contact region as shown in Figure 6.

Figure 7 illustrated the value of the friction force that has been calculated over the sliding contact distance between the counterpart's surfaces.

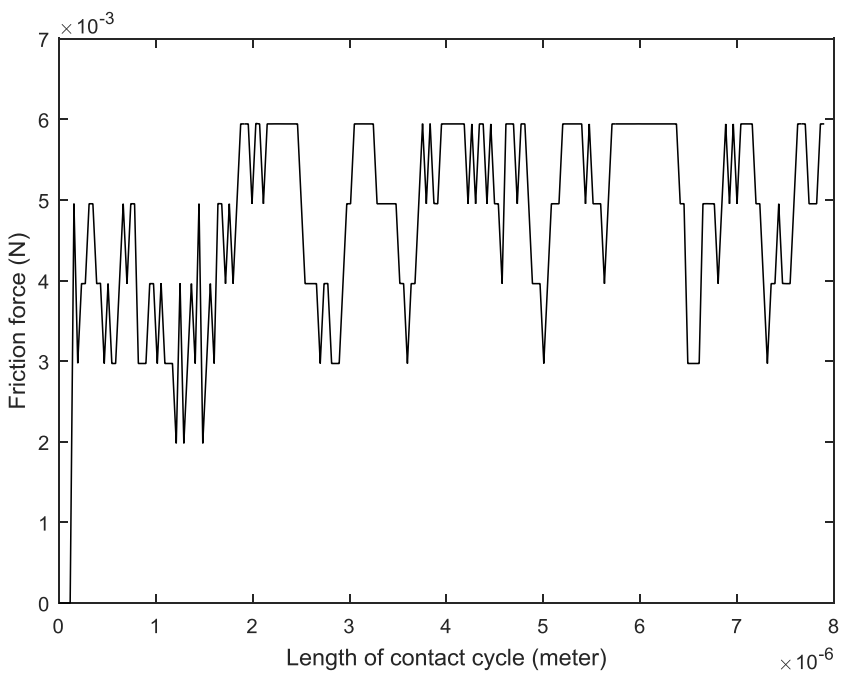

Fig. 7. Friction forces during contact cycle.

Some parts of the above friction force graph look as flat. However, a magnified section of a part of Figure 7 that look flat presented in Figure 8, shows that these parts of the graph are actually not flat and they have a slight variation in their magnitude.

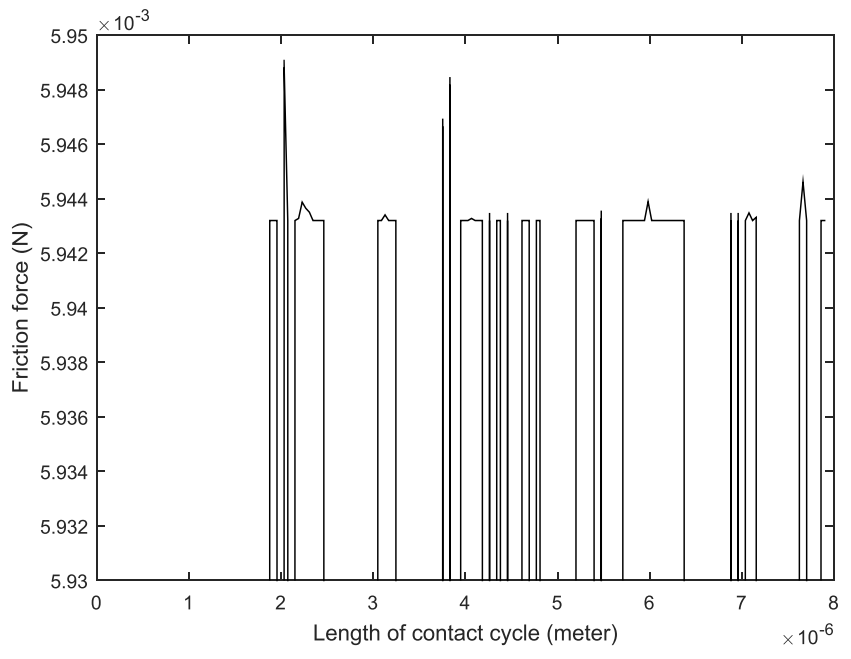

Fig. 8. A magnified part of the friction forces graph.

Figure 9 is presented to show the values of the adhesion force along the silicon microgear MEMS teeth during the contact cycle. The maximum value of the adhesion force has been indicted for the value of $3.2 E-4 \mathrm{~N}$.

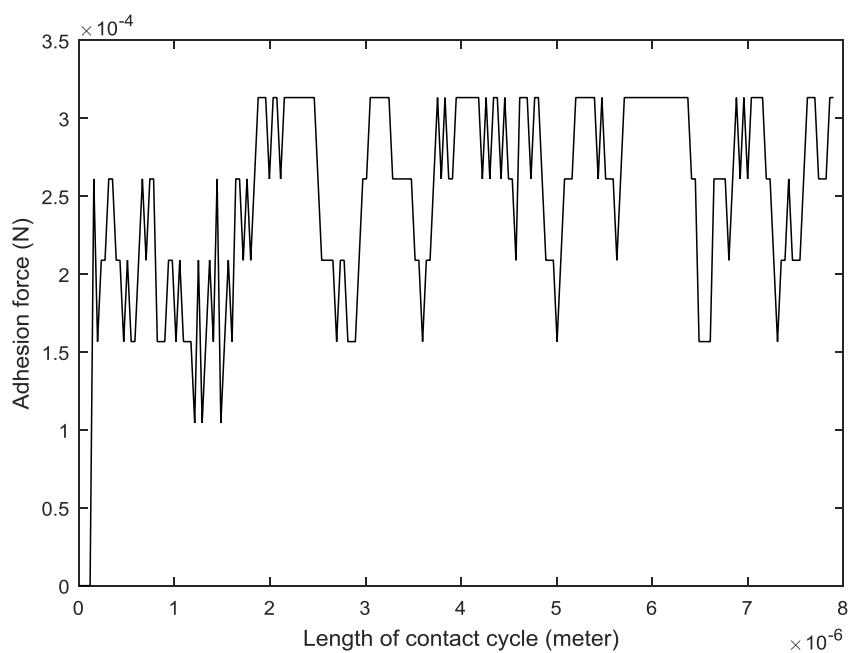

Fig. 9. The adhesion force over the contact cycle.

As it has been explained above, the coefficient of friction is calculated by (8) or (9). Figure 10 shows the values of COF over the contact cycle.

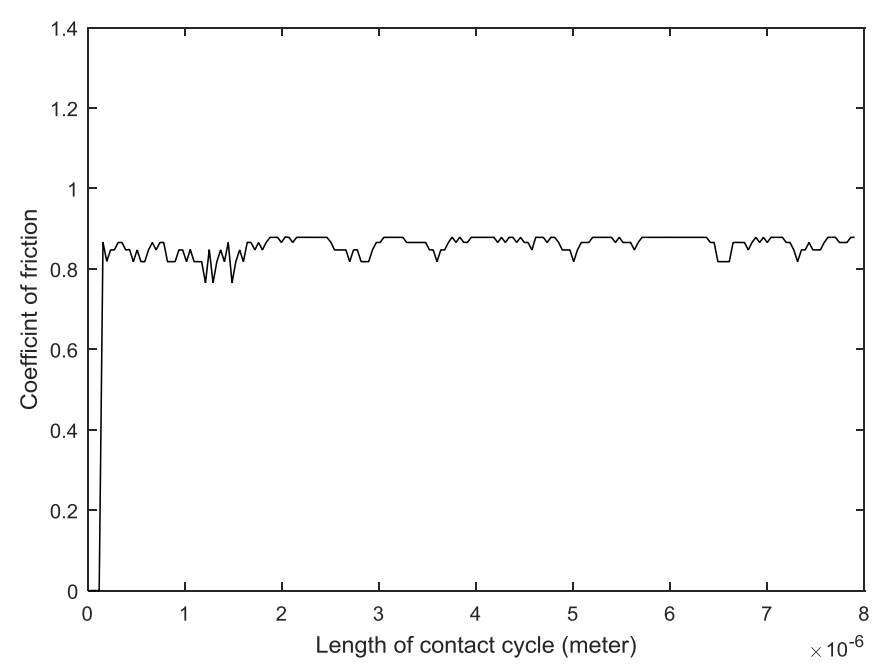

Fig. 10. COF over the sliding contact distance

The above COF values have been calculated assuming that there is no stiction between surfaces. If the values of the external tangential force $F_{t}$ are not sufficient to overcome the friction, i.e. $F_{f}>F_{t}$, then stiction occurs and the microgear cannot work. One can see that the probability of stiction between the clean silicon microgear MEMS teeth working in a high vacuum environment are very high.

\section{FUNCTIONALIZED SURFACES}

Surface chemical modifications are widely applied to reduce surface forces, stiction and the effects of the chemical interaction well known as the cold welding between surfaces in the 
micromachined structure during the release process $[1,5]$. These chemical modifications are often presented as self-assembled (SAM) monolayers of carbosilane, in particular monolayer coatings based on the Octadecyltrichlorosilane (OTS). The coefficient of the friction and the friction force for the functionalized coating of silicon microgear MEMS tooth surface with the SAM OTS have been calculated in the different percentage of wear rate. Firstly the simulations have been performed with fully protected tooth surface (see Figure 11) and then when the wear or damage is started to occur due to the high friction force between the MEMS teeth surfaces or due to operation process.

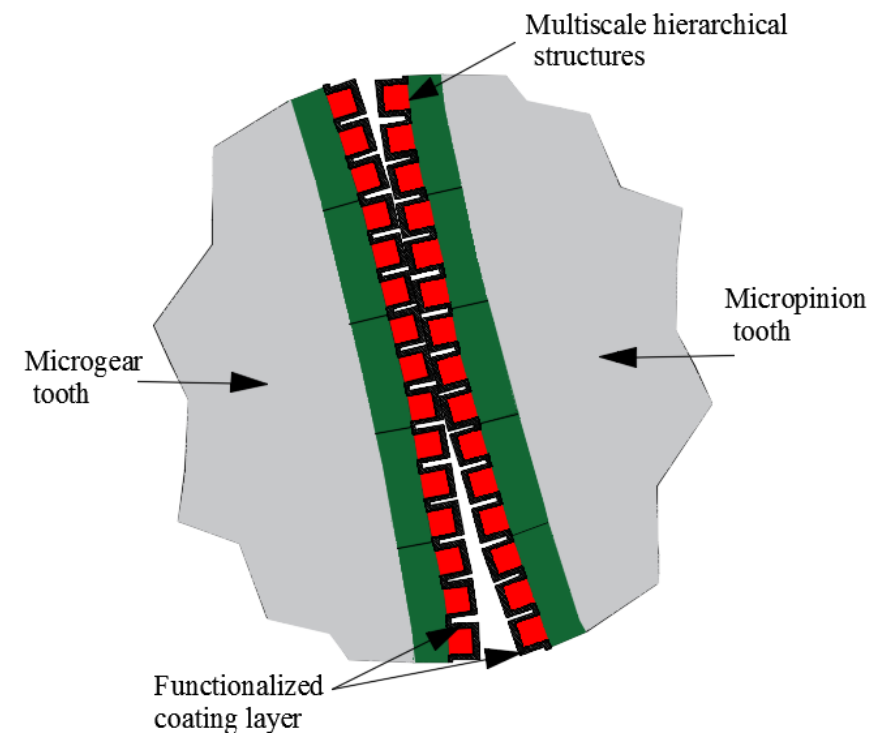

Fig. 11. Functionalized coating layer covered the microgear tooth and the nanoasperity blocks are distributed on the micropinion tooth. The second nanoscale adhesive layer (the second subscale) is represented in green, and the atomic subscale in red.

Our simulations show that if the microgear MEMS tooth surface is fully functionalized with SAM OTS monolayer, the coefficient of friction is 0.185 . This value is quite suitable to continue the operating system without any problem. Hence, no stiction is occurred. If the same gear has non-functionalized surfaces then the COF is approximately 0.9 as shown in Figure 12. If there is some surface wear then the functionalized coating monolayer may be damaged and some its parts may be worn away. Hence, the stiction may occur again between the meshing surfaces. Indeed, as soon as the OTS molecules start to leave the surface, the chemical bonds will begin to generate between the uncovered spaces and the probability of stiction will starts to increase with each particle of coating worn away.

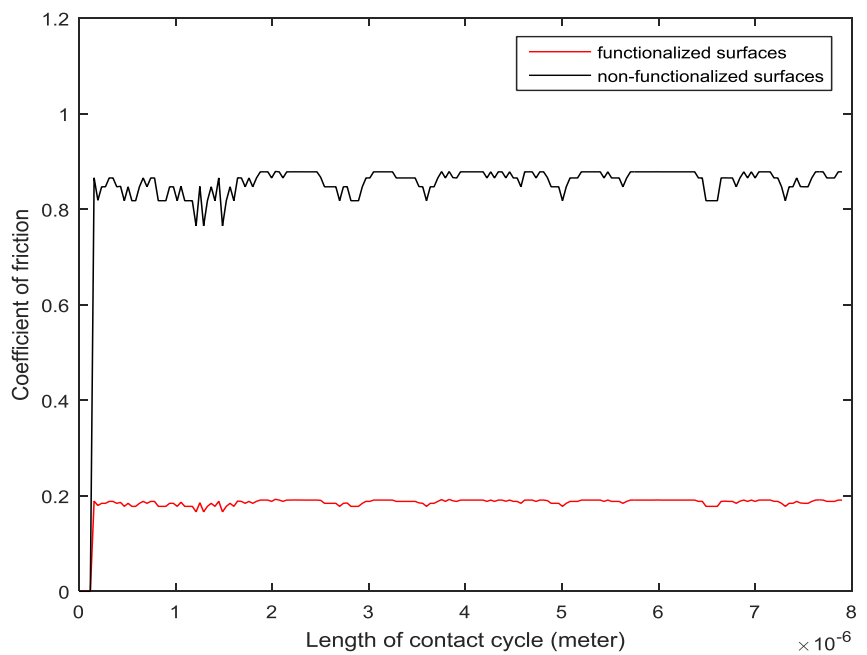

Fig. 12. Comparison of the COF before and after the functionalization of the teeth surface by OTS self-assembly monolayer.

\section{CONCLUSION}

A new approach to modelling of friction and adhesion between the silicon-based microgear MEMS working in a vacuum environment is described. In this approach, for the first time the roughness is represented as multi-block structures covering the entire micro-tooth surface.

Each of the structures is represented by the multiscale hierarchical model of an asperity that consists of two different scales: atomic subscale, where the chemical interactions are significant, and adhesive subscale, where the van der Waals interactions are likely occur. The single asperity model introduced by Savencu and Borodich earlier has been modified to reflect particular features of a microgear MEMS. The total energy dissipated due to interlocking of nanoasperity, dissociation of chemical and van der Waals bonds has been calculated.

It has been shown that if the gear surfaces are not functionalized then the probability of stiction between the clean silicon surfaces is very high. In contrast, the tooth surfaces having functionalized monolayer carbon-based coatings are much less prone to stiction. The wear of the functionalized coating leads to increase of the probability of stiction between surfaces.

\section{ACKNOWLEDGMENTS}

This work was fulfilled in the framework of the CARBTRIB International Network on Nano-Phenomena and Functionality of Modern Carbon-Based Tribo-Coatings. Thanks are due to the Leverhulme Trust for financial support of the Network. The materials of the paper have been presented at the International Conference on Advances in Automotive Technologies (Yildiz Technical University, Istanbul, Turkey, 11-14 October 2016). 
The Iraqi Ministry of Higher Education and Scientific Research that is gratefully acknowledged supported the studies of one of the authors (NA) at the Cardiff School of Engineering. Thanks are also due to the University of Al-Qadisiyah for their support of the studies.

\section{NOMENCLATURE}

$\begin{array}{ll}\text { Symbol } & \text { Definition } \\ \mu & \text { Coefficient of friction } \\ \text { COF } & \text { Coefficient of friction } \\ F & \text { Friction force } \\ N & \text { Normal force in the Coulomb law } \\ A & \text { Adhesion force in some literature } \\ F_{f} & \text { Friction force } \\ F_{N} & \text { Normal force } \\ F_{t} & \text { Tangential shear force } \\ F_{a d h} & \text { Force of adhesion } \\ U_{d i s i} & \text { Total energy dissipated due to different mechanisms } \\ U_{\text {chem }} & \text { energy dissipated due to dissociation of chemical bonds } \\ U_{v d W} & \text { energy dissipated due to dissociation of van der Waals bonds } \\ U_{e} & \text { energy dissipated due to elastic interlocking of counterparts } \\ & \text { surfaces } \\ E^{*} & \text { Equivalent contact Young modulus } \\ \text { E1 } & \text { young modulus of micropinion material } \\ \text { E2 } & \text { young modulus of microgear material } \\ v 1 & \text { Passion's ratio of micropinion material } \\ v 2 & \text { Passion's ratio of microgear material } \\ r_{2} & \text { Raduis of the microgear }\end{array}$

\section{REFERENCES}

1. Ghodssi, R. and Lin, P. (2011). MEMS Materials and Processes Handbook. New York, Springer.

2. Gad-El-Hak, M. (2002). The MEMS Handbook. Boca Raton, FL, CRC Press.

3. Peterson, K. (1999). MEMS Reliability: Infrastructure, Test Structures, Experiments, and Failure Modes. USA.

4. Maboudian, R., Shurst, W. R. and Carraro, C. (2002). Tribological challenges in micromechanical systems. Tribology Letters, 12, pp. 95-100.

5. Maboudian, R., and Howe, R. T. (1997). Critical Review: Adhesion in surface micromechanical structures. J. Vacuum Science and Technology. B, Microelectronics Processing and Phenomena, 15, 1.

6. Zhang, W.-M., Yan, H., Peng, Z.-K. and Meng, G. (2014). Electrostatic pull-in instability in MEMS/NEMS: A review. Sensors and Actuators A: Physical, 214, pp. 187-218.

7. Fonseca, J. D. and Sequera, M. (2011). On MEMS Reliability and Failure Mechanisms. Hindawi Publishing Corporation.
8. Iannacci, J. (2015). Reliability of MEMS: A perspective on failure mechanisms, improvement solutions and best practices at development level. Displays. 37, pp. 62-71.

9. Derjaguin, B. (1934). Molecular theory of friction and gliding. Zhur. Fizi. Khimii (J. Phys. Chemistry), 5, pp. 1165-1176 (Russian).

10. Bowden, F. P., Leben, L. (1938). Nature of sliding and the analysis of friction. Nature, 141, pp. 691-692

11. Bowden, F. P., Leben, L. (1939). The nature of sliding and the analysis of friction. Proc. R. Soc. London A., 169, pp. 371-391.

12. Bowden, F. P., Tabor, D. (1939). The area of contact between stationary and between moving surfaces. Proc. R. Soc. London A., 169, pp. 391-413.

13. Hopcroft, M.A., Nix W.D. and Kenny T.W. (2010). What is the Young's modulus of silicon? Journal of Microelectromechanical Systems. 19, pp. 229-238.

14. Teodorescu, M., Theodossiades, S. and Rahnejat, H. (2009). Impact dynamics of rough and surface protected MEMS gears. Tribology International, 42, no. 2, pp. 197205.

15. Savencu, O. and Borodich, F. M. (2014). Modelling of friction using a structural multilevel hierarchical model of rough surfaces. Proc. NSCM-27: the 27th Nordic Seminar on Computational Mechanics, KTH, Stockholm, pp. 136139.

16. Polonsky, I. A. and Keer, L. M. (1996). Scale Effects of Elastic-Plastic Behavior of Microscopic Asperity Contacts. J. Tribology, 118, pp. 335-340.

17. Polonsky, I. A. and Keer, L. M. (1996). Simulation of microscopic elastic plastic contacts by using discrete dislocations. Proc. R. Soc. London A., 452, pp. 2173-2194.

18. Dean, J. A. (1999). Lange's handbook of chemistry, 15th ed. New York, U.S.A.: McGraw-Hill, Ch.4, p. 50.

19. Lide, D. R. (2003). CRC Handbook of Chemistry and Physics: A Ready-Reference Book of Chemical and Physical Data. New York, U.S.A.: Boca Raton, CRC Press, Ch.9, p. 57.

20. Borodich, F.M. (2011). Contact problems at nano/microscale and depth sensing indentation techniques, Materials Science Forum, 662, pp. 53-76.

21. Borodich, F.M. (2014). The Hertz-type and adhesive contact problems for depth-sensing indentation, Advances in Applied Mechanics, 47, pp. 225-366.

22. Tas, N., Sonnenberg, T., Jansen, H., Legtenberg, R. and Elwenspoek. M. (1996). Stiction in surface micromachining. J. Micromechanics and Microengineering, 6, pp. 385-397. 